\title{
PASSADO: DILEMAS E INSTRUMENTOS DA HISTORIOGRAFIA
}

\author{
PAST: DILEMMAS AND TOOLS OF HISTORIOGRAPHY
}

Por Pietro Costa***

RESUMO: o presente texto confronta os dilemas e desafios do conhecimento do passado humano, apontando os limites e as possibilidades da historiografia. Na avaliação das possibilidades do historiador, o texto aproxima seu ofício com a perspectiva da hermenêutica contemporânea, firmando entre eles um paralelismo compreensivo.

PALAVRAS-CHAVE: historiografia; hermenêutica contemporânea; ofício do historiador.

1. Tentarei refletir em voz alta sobre os instrumentos e sobre o sentido da historiografia. A minha conversa será, porém, mais uma confissão do que uma lição: será o testemunho da minha maneira de entender o 'ofício do historiador' mais do que uma dissertação teórica sobre o método e sobre o objeto da historiografia. Espero, portanto, que possam emergir da discussão outros, e diversos, testemunhos, outras imagens da

* Professor catedrático de História do Direito da Università degli Studi di Firenze, Itália).

**Tradução de Ricardo Marcelo Fonseca, professor de História do Direito da Faculdade de Direito da UFPR, programas de graduação e pós-graduação. Pesquisador do CNPq.
ABSTRACT: This paper is on the challenges and dilemmas regarding human past showing the limits and possibilities of historiography. In evaluating the possibilities given to the historian, the paper links his or her task to contemporary hermeneutics establishing between them a parallelism on understanding.

KEYWORDS: historiography; contemporary hermeneutics; historian's task.

historiografia com as quais se pode abrir um confronto.

Não pretendo referir-me especificamente à historiografia jurídica. Faltará tempo para fazê-lo. A história do direito apresenta problemas específicos que seria interessante afrontar. Ela é, porém, espécie de um gênero: pertence integralmente ao ramo do conhecimento histórico. Uma característica atual do conhecimento histórico é, de fato, de ser não um objeto, mas um ponto de vista: todo aspecto da realidade humana pode ser objeto do conhecimento histórico. Pode-se fazer, e se faz, história de tudo: da política, das religiões, da arte, da música, da agricultura, da sexualidade, do trabalho, da cultura 
material, dos saberes, do direito. Cada uma destas historiografias afronta aspectos específicos da experiência e deve, portanto, dispor de conhecimentos adequados à compreensão do seu objeto. Espera-se que o historiador da música saiba ler as notas de uma partitura e diferenciar uma fuga de uma sonata, que o historiador da arte saiba como pintar um afresco, que o historiador do direito não confunda propriedade com usufruto e o juiz instrutor com o ministério público (mas não por isso se pretende que o historiador da música componha uma sinfonia, que o historiador da arte pinte um quadro ou que o historiador do direito defenda um desafortunado no tribunal).

Existem, portanto, tantas pesquisas historiográficas diferentes quantos são os aspectos da experiência. Todas, porém, dividem uma característica que constitui o seu denominador comum: a de colocar seu objeto, o aspecto da experiência por ele analisado, no passado, em algum momento do passado. O elemento caracterizador da historiografia é justamente uma peculiar e determinante relação com o passado.

É óbvio, vocês dirão, que o historiador ocupa-se do passado. Convém porém tomar a sério esta obviedade. Claro, o tempo, e portanto também o passado, entra em jogo em todo tipo de saber. Para ninguém é possível estudar só o presente imediato. Também o jurista, também o sociólogo estudam fenômenos que se desenvolvem no tempo e, portanto, incluem em alguma medida o passado. Mas o jurista e o sociólogo encerram o passado no presente: interessamse pelo passado se e enquanto ele é absorvido no presente. Para o historiador vige a regra contrária. Ocupando-se seja do direito romano arcaico, seja do direito do século $\mathrm{XX}$, seu objeto é colocado num tempo diverso do seu: o historiador é um especialista do passado.

Refletir sobre a historiografia significa então refletir sobre a relação entre presente e passado. Aqui se faz necessário, porém, outro esclarecimento: não pretendo suscitar um problema de 'filosofia da história'. Não pretendo colocar a famosa pergunta sobre 'quem somos e para onde vamos'. A minha questão é puramente empírica, interior àquele saber especializado que chamamos historiografia. Pretendo perguntar-me como seja possível conhecer o passado (um ou outro aspecto do passado) e qual seja o sentido desta empreitada.

Ora, esta empreitada - conhecer o passado (conhecer algum aspecto da realidade humana em algum momento do passado) - aparentase a um paradoxo: parece, a rigor, uma empresa impossível; parece com a tentativa de conhecer alguma coisa que não é, não existe; alguma coisa que foi, mas não é mais. Não inventamos ainda a máquina do tempo imaginada por Wells. Somos prisioneiros do nosso presente. De que modo então podemos pretender conhecer o passado?

De fato, não podemos nos aproximar do passado diretamente; não podemos ter dele um conhecimento imediato; não podemos nos relacionar com o passado como nos relacionamos com uma experiência que estamos vivendo em primeira pessoa. Podemos conhecer o passado somente por meio daquilo que o passado deixou nas nossas mãos. O mar do tempo retirou-se e abandonou seus detritos e suas sedimentações sobre a praia: não vemos o mar e podemos somente recolher aquilo que ele depositou na margem. 
Recebemos do passado as mensagens na garrafa que afortunadamente nos chegaram. Ou seja: não podemos conhecer a realidade transcorrida diretamente, mas só indiretamente, através das mensagens, os testemunhos, os resíduos que nos chegaram: desapareceu o fogo, mas restam as cinzas e a fumaça. Por meio dos sinais, buscamos representar para nós 'aquilo que não existe'.

O historiador trabalha sobre sinais, testemunhos. Estes sinais podem ser os mais variados: um instrumento de trabalho, um fóssil, um monumento, um resto de uma imagem, o fragmento de um vaso, um texto escrito (e esta última categoria, para o historiador dos saberes e também para o historiador do direito, tem uma importância determinante, senão exclusiva). $\mathrm{O}$ historiador tem a ver com sinais, com testemunhos, com textos: é deles que deve colher o significado para representar, por meio deles, a experiência transcorrida e desaparecida.

Compreender um texto, captar-lhe o sentido, é uma operação específica que toma o nome de interpretação. Se a história é (necessariamente) história dos textos (narrativa construída por meio de textos), ela é uma atividade cognoscitiva do tipo hermenêutico. Os dilemas e os instrumentos da historiografia são, com as necessárias adaptações, os dilemas e instrumentos de toda atividade interpretativa.

Se isso é verdadeiro, abre-se para o historiador que queira refletir criticamente sobre o próprio trabalho um grande espaço de investigação: um espaço cultivado por aquela tradição hermenêutica cujo marco inicial podemos identificar ao menos em Schleiermacher e vemos desenvolver-se impetuosamente até os nossos dias.
Obviamente, limito-me a indicar-lhes um promissor terreno de caça, sem poder atravessá-lo. Vou me limitar a trazer as principais conseqüências do assunto: da recondução da historiografia à hermenêutica.

$\mathrm{O}$ historiador interpreta textos. O que significa interpretar? Para uma longa tradição, vital até tempos recentes, interpretar significa tomar o sentido próprio de um texto. O significado de um texto é concebido nessa perspectiva como um núcleo objetivo encerrado no texto; um significado, sempre igual a si mesmo, que o texto torna disponível a qualquer um que saiba manejá-lo com a devida competência. O significado está dentro do texto como a pérola está dentro da ostra: basta abri-la com uma faca pontiaguda e dela se apropriar.

Na verdade, essa reconfortante perspectiva não parece se sustentar diante das mais sofisticadas investigações da hermenêutica do século XX. O texto não encerra um e somente um significado. O texto é muito mais um cruzamento de possibilidades semânticas, tão mais amplo quanto mais sua tessitura é rica e complexa. O texto não exibe 'sozinho' seu significado: o significado é produzido, mais do que descoberto, pelo leitor. O leitor menos registra passivamente o significado já dado do texto do que lhe atribui um sentido (entre os tantos possíveis). Conseqüentemente enfraquece a contraposição entre uma proposição 'verdadeira' (a única interpretação verdadeira) e uma interpretação falsa: dado um texto, podem existir diferentes (e igualmente plausíveis) atribuições de sentido.

Não existe um texto sem um leitor que lhe atribua o sentido. A hermenêutica contemporânea transforma decididamente em protagonista o leitor, o intérprete, o sujeito. 
Estamos na antípoda do positivismo oitocentista, convicto que nas ciências sociais como nas ciências naturais o pesquisador fosse um observador impassível dos fenômenos, capaz de espelhar a realidade tal como ela era sem que sua personalidade interferisse no processo cognoscitivo. A reflexão hermenêutica sublinha, ao contrário, o papel ativo e criativo do sujeito. O intérprete, e portanto o historiador, não é uma quadro negro sobre o qual imprimem-se os textos. Os textos dizem alguma coisa na medida em que são decifrados e estimulados por um intérprete que intervém no processo interpretativo com todo o peso de sua personalidade.

A interpretação de um texto é uma operação que envolve o intérprete em sua inteira subjetividade. O sujeito de uma operação hermenêutica não é um ser humano genérico: é um indivíduo de carne e osso, é este indivíduo, ligado a um contexto preciso, marcado por inúmeros elementos que conotam a sua personalidade (o país de onde vem, a classe social, a cultura, a língua, a formação profissional). $\mathrm{Na}$ interpretação de um texto o intérprete, o historiador coloca em jogo todos os aspectos de sua personalidade que constituem, todos juntos, a condição de possibilidade da atividade hermenêutica. Em síntese: é a partir do mundo e do tempo ao qual cada um de nós pertence que interpretamos textos e narramos histórias.

O historiador pertence inteiramente ao seu tempo, ao seu presente, e é a partir do seu presente que ele olha o passado tentando reconstruir por meio de testemunhos disponíveis o mundo que perdemos. Radicado no presente, o historiador faz de tudo, porém, para ir além dele. Até que ponto uma tal empresa é possível? Se pertencemos inteiramente ao presente, de que maneira podemos atingir uma realidade a ele irredutível?

Estamos diante de um dos mais difíceis dilemas da hermenêutica. De um lado, o intérprete não compreende o passado senão a partir do seu presente, da cultura, da linguagem, dos conceitos que ele divide com a sociedade e com a comunidade profissional de que faz parte. De outro lado, porém, o intérprete é tal enquanto está disposto a abrirse aos estímulos de textos distantes e diferentes, que ele tenta tomá-los na sua alteridade com relação aos seus hábitos culturais imediatos.

Uma corrente hermenêutica recente, respeitável sobretudo na história e na teoria da literatura, a corrente desconstrucionista, escolhe uma solução radicalmente subjetivista. Para o desconstrucionismo, o intérprete não decifra um texto, não atribui a ele um sentido interno ao próprio texto; o intérprete reescreve livremente o texto, adapta-o às suas necessidades e suas expectativas. O protagonismo do sujeito torna impossível o conhecimento do objeto. O texto interpretado torna-se um mero componente interno do discurso interpretante e conseqüentemente cai qualquer possibilidade de confrontar-e com uma realidade diferente da nossa, de entender um texto na sua autônoma capacidade de produzir significado; e cai portanto a própria possibilidade de uma interpretação autenticamente historiográfica, a possibilidade de conhecer o passado na sua alteridade e especificidade com relação ao presente.

É possível escapar do radical niilismo historiográfico da perspectiva desconstrucionista? Segundo esta perspectiva, 
a historiografia seria substancialmente o espelho de um presente do qual o historiador é irremediavelmente prisioneiro. Porém, o presente é realmente uma prisão sem janelas e portas? Ou é muito mais um precioso observatório? Claro, é um observatório colocado num certo tempo e num certo espaço, que impõe ao historiador um determinado e setorial 'ponto de vista' (o olhar do historiador não é o olhar de Deus), mas ao mesmo tempo lhe fornece os instrumentos óticos com os quais é possível focar objetos distantes no tempo.

Trata-se de cumprir uma aposta, de sabor quase pascaliana: não dispomos de instrumentos que nos dêem certezas. Nada nos garante que não estamos projetando no passado o nosso presente, ao invés de efetivamente entrarmos em contato com uma realidade outra com relação à nossa, diferente e distante. A aposta do historiador é justamente a tentativa de dizer alguma coisa sobre mundos distantes e perdidos; de tecer uma narrativa que se propõe a dilatar os confins do imediatamente presente.

Não temos certezas, mas podemos usar de expedientes de técnicas que diminuam o risco de transformar a historiografia num mero jogo de espelhos. Pensamos em uma prática que pode nos ensinar muito sobre a lógica da interpretação: a tradução. Traduzimos continuamente de um texto a outro. $\mathrm{O}$ tradutor reescreve na sua língua o texto traduzido. Nada nos garante que o tradutor não seja um traidor; e, todavia, não por isto renunciamos a traduzir. Para que esta prática hermenêutica funcione são necessários, porém, expedientes refinados. É necessária, em primeiro lugar, uma peculiar atitude mental do tradutor: ele deve colocar-se a serviço do texto e fazer todos os esforços para reconstruir seu sentido colocando-o no seu contexto (no contexto do autor e na época a qual pertence o autor). Traduzir é colocar-se a serviço de um texto: o tradutor é tal enquanto renuncia ao monólogo em favor do diálogo. Também para o historiador vale a mesma regra: o historiador acumula os testemunhos para colocar o texto no tecido histórico-cultural do qual provém. A lógica do historiador é uma dia-lógica: seu objetivo não é reduzir o outro a si mesmo, o passado ao presente, mas é instaurar um diálogo, usar todos os instrumentos disponíveis para entrar em relação com um mundo diverso do seu.

Em segundo lugar, a tradução é um confronto entre linguagens: é a reescritura do texto traduzido em uma língua diversa. Para que isso seja possível, é necessário que o tradutor dedique a mesma atenção a duas linguagens: a linguagem da qual ele traduz e a linguagem na qual ele traduz. É exatamente essa a situação hermenêutica do historiador. O historiador se movimenta a partir do seu presente: trabalha ativando as categorias lingüísticas e conceituais que lhe são ofertadas pela cultura. É esta a linguagem de que dispõe para compreender a linguagem do passado, para decifrar seus testemunhos, para narrá-los a nós. A linguagem do seu presente, porém, não é o objeto da sua pesquisa, mas é somente o seu (indispensável) instrumento: o objeto de sua pesquisa é a linguagem do passado. A operação historiográfica é o confronto entre duas linguagens: a metalinguagem do historiador (a linguagem com a qual ele trabalha) e a linguagem-objeto (a linguagem sobre a qual ele trabalha).

Convém estar ciente desse mecanismo. Esta ciência é o principal instrumento de que 
dispomos para evitar o jogo de espelhos, para evitar que nossa narração, fingindo representar o passado, fale na realidade somente do nosso presente. Se realmente queremos dialogar com o passado, devemos verificar de modo acurado as categorias conceituais que empregamos para compreendê-lo e para comunicar sobre ele. Devemos fazer um uso instrumental e não final, operacional e não essencialístico das linguagens e dos construtos teóricos que usamos (e os que não podemos usar) para narrar o passado, para interpretar os textos. Devemos fazer uso, com função hermenêutica, não de uma teoria forte, mas de uma teoria fraca, não de uma teoria fechada, mas de uma teoria aberta. Em outras palavras: devemos empregar a linguagem do nosso presente não para afirmar verdade (a nossa verdade), mas para formular perguntas. O historiador não tem necessidade de asserções, mas de perguntas: ele toma do seu presente os estímulos e os materiais que servem para trazer problemas, para colocar perguntas: são estas perguntas, as perguntas instigadas pelo seu presente, que lhe permitem selecionar no conjunto caótico dos textos do passado, os textos pertinentes; e serão estes textos a oferecer respostas às perguntas previamente formuladas.

Com esses expedientes, é possível aceitar a aposta: é possível tentar dilatar os limites do nosso presente e mover-se em direção à pesquisa de mundos diversos e distantes no tempo, ainda que se saiba poder oferecer não uma representação total e indiscutível da realidade passada (os mundos desaparecidos são irrecuperáveis), mas somente uma reconstrução parcial e hipotética.

É necessário insistir sobre o caráter conjectural da exploração historiográfica.
Isso depende não apenas da discrepância entre a documentação disponível e a realidade desaparecida, mas sobretudo do fato que o historiador, como dizia, não trabalha diretamente sobre a realidade, mas passa pelo filtro obrigatório dos textos, dos discursos, dos sinais. Enquanto operação hermenêutica, o conhecimento historiográfico é um conhecimento, por assim dizer, de segundo grau: procede do sinal ao significado, do visível ao invisível, sem poder dispor de nenhum ponto fixo, de nenhuma ancoragem segura.

Cai por terra então a possibilidade de distinguir a historiografia da narrativa, a verdade da invenção, os acontecimentos das imagens, a realidade da possibilidade? Creio que não. Creio que para diferenciar claramente a narrativa da historiografia, fazendo com que estes dois gêneros literários sejam inconfundíveis, intervenha a 'decisão' que orienta e inspira a estratégia heurística do historiador e impõe regras específicas ao seu procedimento: a decisão de buscar a 'verdade' e, portanto, a necessidade de fornecer 'provas'. É sugestivo, deste ponto de vista, a proximidade entre dois especialistas da interpretação aparentemente muito diferentes entre si: o historiador e o juiz. Foi o filósofo Guido Calogero que, nos anos trinta, chamou a atenção sobre a analogia que transcorre entre as operações hermenêuticas do historiador e do juiz e recentemente Carlo Ginzburg desenvolveu brilhantemente este tema ${ }^{1}$ sublinhando, para ambos, a importância dada para a tensão entre a verdade e a retórica da prova. E vale, enfim, para ambos,

1 Trata-se do livro GINZBURG, Carlo. Il giudice e lo storico: considerazioni in margini al processo Sofri. Torino: Einaudi, 1991 (N. do T.). 
conseqüentemente, o caráter conjectural e incerto de suas afirmações: as suas argumentações se fundam sobre sinais e indícios; é assimilável, como escreve Ginzburg, à lógica de Sherlock Holmes ou ao comportamento do caçador que pelos rastros chega ao animal'2; exerce-se não sobre o caráter incontroverso da dedução racional, mas sobre o caráter persuasivo do razoável.

É, portanto, uma dupla e difícil aposta que o historiador aceita: em primeiro lugar, a aposta de conseguir dilatar o horizonte do presente estendendo-se em direção a mundos distantes e desaparecidos para buscar suas características originais, a tentativa de estabelecer uma relação, de edificar uma ponte entre realidades diversas e distantes (entre a cultura do presente e as culturas do passado); em segundo lugar, a aposta de escrever uma narrativa sustentada pelo pathos da verdade, ainda que tendo consciência do caráter fragmentário do resultado e do caráter hipotético e conjectural das argumentações.

É necessário, porém, colocar uma indagação conclusiva. Por que empenhar-se nessa difícil e hipotética reconstrução de mundos perdidos? Poderíamos, afinal, colocar uma indagação brutal: para que serve o conhecimento histórico? À luz do paradigma historicista, ainda dominante, ao menos na Itália até o fim dos anos setenta, a resposta a esta pergunta é, por assim dizer, automática, ditada pelo próprio paradigma: para o historicista, o presente depende inteiramente do passado e só é compreensível a partir dele.

2 Evocação do celebre texto de Ginzburg intitulado 'Sinais: raízes de um paradigma indiciário', publicado em português em GINZBURG, Carlo. Mitos, emblemas, sinais: morfologia e história. São Paulo: Companhia das Letras, 1989, p. 143/179 (N. do T.)
A realidade é uma cadeia ininterrupta de eventos, em que só o antecedente pode explicar o subseqüente. Mas não estou seguro que hoje um jovem europeu, ou californiano ou brasileiro atribua o mesmo grau de indiscutível evidência à tese historicista. No que me diz respeito, para dar uma resposta, a minha resposta, à pergunta sobre o sentido da historiografia, mais do que apoiar-me na contínua e íntima conexão entre passado e presente, apresentaria a historiografia como uma ocasião para entrar em contato com o distante e com o diferente.

Tento explicar-me com a metáfora da viagem. A historiografia é uma viagem no tempo: uma frágil e arriscada peregrinatio em mundos distantes e estranhos. Para que serve uma viagem historiográfica no tempo? São possíveis diversas respostas. Para o historicista, viajar no tempo significa traçar uma linha reta e segura entre o passado e o presente, imergir o presente no passado para entender as raízes do primeiro e a direção de sentido do segundo. Para o historicista, a história é útil para entender o presente. Viajar é útil. Porém, é possível também uma atitude diferente: a atitude do viajante distraído e curioso. Para esse viajante, não existe uma linha segura e reta que ligue o passado e o presente. O passado é uma realidade complicada e confusa: não se pode reconstruíla em sua totalidade; ela é feita somente por conjecturas e aproximações; não parece revelar uma direção unívoca e segura; não mostra o sinal de uma linha ou de várias linhas contínuas e claras; apresenta-se muito mais como um emaranhado de segmentos que se entrecruzam, perdem-se, recomeçam, interrompem-se; não é uma linha e nem um círculo, muito mais um labirinto. Para este 
viajante o sentido da viagem não está na ligação com o presente, mas sim na experiência do estranhamento. O sentido da viagem não é a pesquisa do familiar, mas sim o confronto com o diferente.

Uma tal viagem no tempo é assimilável à viagem no espaço (que às vezes é também uma viagem no tempo) feita pelo antropólogo. Também o antropólogo, já há mais de um século, deixou para trás os preconceitos eurocêntricos para valorizar o complexo cultural das mais variadas sociedades e tomar delas o sentido autêntico. Apresentam-se ao antropólogo os mesmos desafios que o historiador enfrenta: a impossibilidade de sair de fora de si mesmo, o seu integral radicar-se na sociedade do seu presente e ao mesmo tempo a aposta de entender normas, usos, formas de vida profundamente diferentes e distantes. Também o antropólogo é um especialista do alhures: um viajante desinteressado, um profissional da curiosidade.

O núcleo da sua experiência (o sentido de sua aposta - tendencialmente - impossível) é o alargamento dos confins do mundo, a tentativa de tornar menos peremptória e exclusiva a forma de vida que nos é familiar: o idolon abatido pela moderna antropologia cultural é o eurocentrismo. A identificação com um lugar não é, porém, o único vínculo que nos aprisiona. Igualmente tirânico é um outro idolon: o cronocentrismo, a assunção do presente como nosso horizonte fechado e exclusivo. A aposta da historiografia, como a da antropologia cultural, é justamente evocar a existência ou a possibilidade de outros tempos e outras formas de vida. 